\title{
Concepts of Intrinsic Value and Integrity of Plants in Organic Plant Breeding and Propagation
}

\author{
E. T. Lammerts van Bueren,* P. C. Struik, M. Tiemens-Hulscher, and E. Jacobsen
}

\begin{abstract}
The natural approach taken by organic agriculture obviates the use of synthetic agrochemicals and emphasizes farming in accordance with agroecological principles. Also implicit in this approach is an appreciation for the integrity of living farm organisms, with the integrity being evaluated from a biocentric perspective. The ethical value assigned to integrity of organisms has challenged us to develop criteria for evaluating both integrity and breeding techniques. For cultivated plants, integrity refers to their inherent nature, their wholeness, completeness, species-specific characteristics, and their being in balance with their (organically farmed) environment. We evaluate integrity using criteria derived from four different perspectives: integrity of life, plant-specific integrity, genotypic integrity, and phenotypic integrity. These criteria were used to assess whether existing breeding and propagation techniques violate the integrity of crop plants. In vitro techniques and techniques that engineer at the DNA level appeared to be incompatible with the integrity of crops, with the exception of use of DNA markers. On the other hand, breeding techniques that work at the level of breeding, evaluation, and selection for whole plant performance, and which do not break reproductive barriers between species, may conform to the principles of organic farming. In the selection process, the so-called breeder's eye can be developed to become a more consciously applied instrument for perceiving and assessing aspects of the wholeness or phenotypic integrity of a plant. Thus, the challenge given by the organic community to breeders implies the further development of scientific approaches, evaluation, and choice of breeding techniques, and the systematic development of the respectful and artful eye of the individual breeder.
\end{abstract}

$\mathrm{M}$ ODERN CULTIVARS of field-grown crops do not satisfy all the requirements and demands of organic agriculture. Therefore, more attention should be given to breed specific cultivars adapted to the agronomic conditions on organic farms and complying with the philosophy of organic agriculture. Organic agriculture is often characterized as a natural way of farming, mostly referring to the absence of synthetic chemical inputs, such as chemical fertilizers, herbicides, and pesticides (Anonymous, 1991; IFOAM, 2002). To avoid the use of chemical fertilizers and pesticides in organic agriculture, agroecological principles are to be applied to enhance the self-regulatory capacity of the agroecosystem. An important tool is stimulating functional diversity at different levels of management: The farm level, the crop-

E.T. Lammerts van Bueren and M. Tiemens-Hulscher, Louis Bolk Inst., Hoofdstraat 24, NL-3972 LA Driebergen, the Netherlands; P.C. Struik, Wageningen Univ., Dep. of Plant Sci., Crop and Weed Ecology Group, Haarweg 333, 6709 RZ Wageningen, the Netherlands; E. Jacobsen, Wageningen Univ., Dep. of Plant Sci., Laboratory of Plant Breeding, Binnenhaven 5, 6709 PD Wageningen, the Netherlands. Received 15 Oct. 2002. *Corresponding author (e.lammerts@ louisbolk.nl).

Published in Crop Sci. 43:1922-1929 (2003).

(c) Crop Science Society of America

677 S. Segoe Rd., Madison, WI 53711 USA ping system, the crop species, and the cultivar. Organic farmers require cultivars that can be multiplied and grown in the organic farming system with no undue negative effects on the health and function of the agroecosystem. Cultivars should therefore have the ability to perform under low input of organic fertilizers, a good root system, the ability to interact with beneficial soil microorganisms and to suppress weeds, and the ability to produce a healthy crop and healthy propagules (Lammerts van Bueren et al., 2002a,b, 2003).

However, Verhoog et al. (2003) pointed out that the naturalness of organic agriculture not only refers to (i) the avoidance of inorganic, chemical inputs, and (ii) to the application of organic, agroecological principles, but also (iii) implies acknowledgment of integrity. The general appreciation for working in consonance with natural systems in organic farming extends itself to the regard with which members of the movement view individual species and organisms. Species, and the organisms belonging to them, are regarded as having an intrinsic integrity. This integrity exists aside from the practical value of the species to humanity and it can be enhanced or degraded by management and breeding measures. This kind of integrity can only be assessed from a biocentric perspective (see below). Organic agriculture assigns an ethical value to this integrity, and encourages propagation, breeding, and production systems that protect or enhance it.

After providing definitions and describing the species concept in organic agriculture, our paper will concentrate on the philosophical and ethical meaning of the third element of naturalness - the integrity of plants and will discuss the implications of this concept of integrity for organic propagation and breeding schemes. The concept of integrity is generally closely linked to the broader concept of intrinsic value. Both concepts are usually only applied to the animal kingdom. We will evaluate how they are used for animals and then apply and adapt them to plants. This analysis will result in an assessment of the naturalness of the various plant breeding and propagation techniques and thus of their acceptability for use in organic agriculture.

\section{Definitions}

Naturalness, as used in the context of organic crop production, refers to the avoidance of inorganic, chemical inputs; to the application of organic, agroecological principles in crop and farm management; and to respect for the integrity of plants.

The intrinsic value of plants indicates that a plant is ethically relevant, and has a value of its own, indepen-

Abbreviations: CMS, cytoplasmic male sterility; IFOAM, International Federation of Organic Agriculture Movements. 
dent of the instrumental value for humans. Ethically relevant means that humans respect the intrinsic value of the plant and take it into account in deciding their actions. What is regarded as being ethically relevant depends on the attitude people choose to have toward nature. From the biocentric perspective (see below), all plants, both cultivated and wild, have an intrinsic value based on respect for their integrity and autonomy.

The integrity of plants refers to their nature or way of being, their wholeness, completeness, their speciesspecific characteristics, and their being in balance with the species-specific environment. Taking integrity seriously does not imply that man cannot interfere with plants. In organic agriculture, respect for the integrity of cultivated plants implies that their characteristic nature is given weight next to other arguments when deciding how to work with them in breeding, propagation, and cultivation.

In the context of the discussion about the crossing of the boundaries between species, organic agriculture uses the biological species concept. This implies that belonging to a certain species means belonging to a group or natural entity of individuals that can exchange genetic information among themselves, but are genetically separated from other species by reproductive barriers. The boundaries of plant species are not always strict. Therefore, the use of crosses among closely related species is allowed in organic breeding provided the hybridization is possible without in vitro techniques (e.g., embryo rescue and plant regeneration) (see below).

\section{MATERIALS AND METHODS}

This paper is partly the result of an extensive literature research. The main body of information and ideas, however, was collected by a think tank led by the first author and based on several research and discussion projects conducted in the period 1997 to 1999 (for details, see Lammerts van Bueren et al., 1998, 1999) and in 2001 (for details, see Lammerts van Bueren and Luttikholt, 2001; Lammerts van Bueren et al., 2001) by order of the Dutch Ministry of Agriculture, Nature Conservation and Fisheries. More than 30 national and international workshops were held with farmers, breeders, seed producers, and traders, researchers, and policymakers to define ecological criteria for assessment of the suitability of breeding and propagation techniques for organic plant breeding. The concept of integrity was at that time not yet developed for plants, and could not be included as an ethical criterion in these assessments. A project was conducted from 1999 to 2001 to define the concept of naturalness for organic agriculture, including the concept of integrity of life (Verhoog et al., 2003). The results of this project challenged the authors of the current paper to further develop the concept of integrity of plants as a criterion for assessing breeding and propagation techniques for organic agriculture. The first and third authors are specialists in organic plant breeding and propagation; the second author is a specialist in conventional plant propagation, whereas the fourth author is an expert in molecular plant breeding.

\section{The Need to Unravel Ecological and Ethical Criteria to Assess Breeding and Propagation Techniques for Organic Agriculture}

In this section, we will give a short overview of the discussions on assessing current breeding and propagation techniques for organic agriculture which took place in the Netherlands and other European countries in the 1990s.

In the organic sector, the discussion on the acceptability of certain breeding techniques started with respect to asexual transgenic modification (transgenesis). No transgenic modification was allowed in the standards of the International Federation of Organic Agriculture Movements (IFOAM) in 1993 or in the EC-directive 2092/91 in 1999. Bullard et al. (1994) described the underlying arguments of the IFOAM: they were mainly ecological (e.g., further industrialization of agriculture, new level of risks, threats to biodiversity) with only a first indication of an ethical argument [no respect for the inherent nature of (cultivated) plants]. The ethical argument was not further conceptualized. In 1997, the Dutch government asked the Louis Bolk Institute to elaborate the organic viewpoint on all modern plant breeding techniques and to outline criteria for future development of organic plant breeding (Lammerts van Bueren et al., 1998, 1999). This assignment resulted in position papers leading the discussion at the national and international level, and providing a framework for assessing the conformity of current breeding and propagation techniques to principles of organic agriculture. The position papers were based on three key ecological principles: (i) closed production cycles, (ii) natural self-regulation, and (iii) agrobiodiversity. These principles are relevant at the farming system level and have correlations on the level of the plant or crop (a biological system at a lower level of aggregation) and to the socioeconomic level (a socioeconomic system at a higher level of aggregation), see Table 1. From an ecological point of view, a more-or-less closed production cycle at the farm level may have its equivalent at the plant level in the ability to fulfill its own life cycle from seed to seed without artificial environmental conditions (in vitro techniques) while maintaining its genetic constitution (no killer genes, preferably no hybrids). Natural self-regulation at the farm level can be translated to the plant and crop level as a high ability to adapt to changes in the environment and independence from chemical protection. Agrobiodiversity at the farm level can be translated to (functional) genetic diversity with respect for reproductive barriers at the plant and crop level. These criteria will ensure sustainable, ecologically efficient use and development of plants with benefits to a sound, agroecological farming system.

As for the conversion of the key ecological principles from

Table 1. Key ecological criteria for organic farming systems converted to the plant and socioeconomic levels (based on Lammerts van Bueren et al., 1999).

\begin{tabular}{lll}
\hline Plant and crop level & \multicolumn{1}{c}{ Farming system level } & Socioeconomic level \\
\hline Self-reproductive ability & $\begin{array}{c}\text { Production cycles with minimum external } \\
\text { inputs and input loss } \\
\text { Natural self-regulation }\end{array}$ & $\begin{array}{c}\text { Close and local interaction between farmers, trade, industry, } \\
\text { breeders and consumers } \\
\text { Adapt existing regulations by incorporating organic } \\
\text { principles (e.g., in relation to cultivar testing) } \\
\text { Cultural diversity represented by many different breeding } \\
\text { programs }\end{array}$ \\
$\begin{array}{l}\text { High genetic diversity within } \\
\text { reproductive barriers }\end{array}$ & Agrobiodiversity & .
\end{tabular}


the farm level to the socioeconomic level, a successful plant breeding program may be based not only on a close plant $x$ environment interaction, but also on a close cooperation between farmers and breeders (participatory approach), optimizing the use of exchange of knowledge and experience found with different specialties (Jongerden et al., 2002). In modern plant breeding, regulations play an important role, but current legislation, for instance on the authorization of new cultivars, is in some cases a bottleneck in the marketing of cultivars suitable for organic farming (Lammerts van Bueren et al., 2001). Further steps and research are needed to adapt the regulations to organic agriculture. The third criterion mentioned in Table 1 concerns cultural diversity. Cultural diversity represented by many different breeding programs in different regions is a value on its own, but also a condition for genetic diversity.

In the report on the evaluation of modern breeding techniques (Lammerts van Bueren et al., 1999), no explicit reference was made to the terms intrinsic value and integrity, as they were at that time politically sensitive and not yet conceptualized for plants. The term integrity of plants came up in a workshop held in 2001 for European experts in organic plant breeding and propagation (Lammerts van Bueren and Luttikholt, 2001), but was linked to the ecological criteria at the plant and crop level mentioned in Table 1. Therefore, this workshop did not contribute to further transparency in the ethical evaluation of modern breeding techniques for organic agriculture.

To unravel the ethical and ecological elements in the discussion, it is necessary to further elaborate the meaning and possible instrumentalization of the concept of integrity of plants. This is the aim of this contribution. Therefore, we will first describe the way this concept of integrity has developed in the field of animal production, and subsequently how we can apply it to the field of plant production.

\section{Concepts of Intrinsic Value and Integrity of Animals}

The concept of intrinsic value implies that some natural entity has ethical relevance. Whether people can ascribe intrinsic value to natural entities or not depends on (see also Verhoog et al., 2003) (i) their basic attitude toward nature (man as a ruler, a steward, a partner with nature or a participant in nature; Zweers, 1989, 2000; Kockelkoren, 1993, 1995); and (ii) their normative bioethical perspective.

The basic attitude of man as a ruler or steward is mancentered. It emphasizes nature as a producer of raw material for human aims. Man as a steward restrains the drive for exploitation of nature because of the duty to leave natural resources for future generations. Having partnership as a basic attitude implies that humans have to take into account the needs and interests of living beings because they have intrinsic value. For the participant in nature, it is important to identify himself with nature because all beings in nature depend on each other. These basic attitudes toward nature are reflected in different normative, bioethical perspectives. In the anthropocentric perspective, only human beings are ethically relevant, out of respect for their freedom, autonomy, and individuality. This means that humans have no direct ethical responsibilities toward nature. In a zoocentric perspective, human beings and sentient animals are ethically relevant, out of respect for their feelings and ability to suffer pain. In the biocentric perspective, all living entities are considered ethically relevant, out of respect for their integrity or naturalness. This means that the inherent nature, wholeness and independence are taken into account in making decisions on the exploitation of nature. In an ecocentric, bioethical perspective, not only individual organisms, but also species and ecosystems are ethically relevant, out of respect for their integrity.

Long before the concept of intrinsic value emerged in modern plant production, it was recognized for animals in agriculture and medical research. The Netherlands was the first country to recognize intrinsic value in an official government statement in 1981 (Anonymous, 1981). This triggered an international discussion on underlying concepts of intrinsic value and integrity of animals for ethical evaluation (Brom and Schroten, 1993; Brom, 1999). When animals are instrumentalized they are considered to merely have an instrumental value (extrinsic value), but not a value of their own (intrinsic value) (Verhoog, 1992). The concept of the intrinsic value of animals refers to the inherent, noninstrumental value of animals, indicating that animals are ethically relevant. The intrinsic value is ascribed to animals independent of their utility for humans, out of respect for their otherness and their being more-or-less autonomous.

Once acknowledged, the intrinsic value of animals became ethically relevant in decisions on human exploitation of animals. Until 1992, the concept of intrinsic value was only used for sentient (vertebrate) animals, and was made operational in terms of animal health and welfare. The Dutch Animal Health and Welfare Act of 1992 refers to all animals, and the concept of integrity was included. The emphasis is no longer on what an animal experiences but also on its characteristic nature. Here we see a shift from a zoocentric to a biocentric, bioethical perspective.

The concept of animal integrity can be seen as part of the concept of intrinsic value, next to animal health and animal welfare (De Cock Buning, 1999). Integrity refers to respect for the characteristic nature or way of being of animals, their wholeness, completeness, their species-specific characteristics, and their being in balance with the species-specific environment (Rutgers and Heeger, 1999). The concept of animal integrity was introduced in the ethical evaluation of transgenic animals to deal with those moral aspects that go beyond animal health and animal welfare. Crossing barriers between animal species was interpreted as a violation of their integrity.

\section{Intrinsic Value and Integrity of Plants}

Reflection on the impact of intervention on the integrity of plants first occurred when genetic engineering with plants became an issue in the public debate. Kockelkoren (1993, 1995) was the first to challenge the decision hierarchy present at that time in the Netherlands. In this decision hierarchy, genetic engineering of humans was not allowed. In the case of animals there was a no, unless policy, which meant that genetic engineering of animals was forbidden unless it could be proven that it was done for a significant goal, that there were no alternatives, and that no unacceptable violation of animal well-being and animal integrity was implied. A yes, but policy with respect to plants meant that genetic engineering was allowed, but only if there were no environmental and human health risks. No restrictions were seen for genetic engineering with bacteria in this hierarchy. Kockelkoren tried to go beyond the view that genetic engineering of plants was allowed if there were no environmental or human health risks. He suggested that their intrinsic value should be taken into account. However, his report did not influence Dutch policy because at that time even the concept of integrity of animals was not yet fully elaborated and accepted. Genetic engineering of plants was not yet considered to be a moral problem.

Only recently has this attitude begun to change. Respect for the naturalness and intrinsic value of plants is explicitly mentioned as a consumer concern in several reports (Meyer- 
Abbich, 1997; Anonymous, 1999; Hofmeister, 1999; Heaf and Wirz, 2001; Verhoog, 2002). These reports document an increasing awareness in society that all living creatures, including plants, are to be respected on the basis of their uniqueness. This awareness implies that not only the consequences of human exploitation of plants but also the nature of the intervention itself should be taken into account. This can be seen as a next step toward the acceptance of biocentric ethics in which the intrinsic value of living entities refers to the idea that all organisms have a value of their own.

\section{Different Levels of the Nature of Plants}

To make the intrinsic value of a plant operational from the biocentric perspective, we distinguish the following levels for the nature of plants: (i) the level of the nature of life, (ii) the level of the nature of vegetable life; (iii) the level of the speciesspecific nature; and (iv) the level of the nature of plant and crop individuals.

\section{Level of Nature of Life}

A general characteristic of a living organism in contrast to nonliving materials is that it has a characteristic metabolism and an ability to grow and develop, and to reproduce itself as a more-or-less autonomous entity. Its parts show coherence with the whole of the organism. This means that it is more than merely the sum of different (nonliving) elements, such as chemical compounds or genes. Organisms maintain themselves through self-regulating and self-ordering activities. They have an urge to survive and continue the existence of the species by adapting to changing environmental conditions. At this level, integrity of life is operational and plants and animals have it in common. Integrity of life is the state of wholeness or completeness of a living organism allowing it to perform all its functions. In the context of organic agriculture, this integrity can be violated by, for example, applying (bio)chemical-synthetic inputs that interfere with the self-regulating capacity of living entities.

\section{Level of Nature of Vegetable Life}

Plants belong to a specific realm of nature. Usually they only require elements from the mineral realm to satisfy all their metabolic needs, possess a nutritive system based on photosynthesis, and have rigid cell walls. Plants also differ from animals as plants have no central nervous system and a different way of interacting with their environment or coping with (biotic or abiotic) stress to survive, to grow and develop, and to reproduce independently. A plant does not have the option of moving itself into a different environment and must adapt in place. Plants do have the ability to interact with their rhizosphere and to live in symbiosis with beneficial soil microorganisms. Similarly, plants need to live in an optimal association with bacteria on their leaves, with endophytes as well as with their abiotic environment. At this level, plant- specific integrity is operational. Plant-specific integrity is the state of wholeness or completeness of a plant, allowing it to perform all its plant-specific functions. It can be violated by, for example, growing plants in completely aseptic and artificial environments. In vitro culture or hydroponic culture do not correspond to the plant's worthiness in the organic sense.

\section{Level of Species-Specific Nature}

Plant species differ in life form, life cycle, ontogeny, morphology, metabolism, and reproductive strategies. Each species can be distinguished from other plant species on the basis of these aspects. Its unique characteristics are defined by its genome (with a certain genotypic variation depending on the species). At this species-specific level genotypic integrity is operational. Genetic integrity can be defined as the state of wholeness or completeness of the species-specific genome. This integrity can be violated by bringing in genes from nonrelated species through genetic engineering or by breaking reproductive barriers.

\section{Level of Nature of Plant and Crop Individuals}

Plants are less individualized than animals. Depending on the agricultural sector, the focus of individuality lies either on the crop (agronomic and vegetable growing) or on the individual plant (fruit trees, ornamentals). A plant's appearance is, within the boundaries of its species, plastic. The boundaries of plant production can be challenged by altering the plant's environment or the genome of its progeny. At this level, phenotypic integrity is operational. Phenotypic integrity is the state of wholeness or completeness of an individual plant or crop, including its health. It can be violated from an organic agricultural point of view by, for example, cultivating and developing plants or crops in such a way that they cannot maintain themselves and perhaps cannot complete their life cycle without chemical crop protection.

From a biocentric perspective, organic agriculture acknowledges the intrinsic value and therefore the different levels of integrity of plants as described above. The consequence of acknowledging the intrinsic value of plants and respecting their integrity in organic agriculture implies that the breeder takes the integrity of plants into account in his choices of breeding and propagation techniques. It implies that one not merely evaluates the result and consequences of an intervention, but in the first place questions whether the intervention itself affects the integrity of plants. From the above described levels of the nature of plants and its characteristics, a number of criteria, characteristics, and principles for organic plant breeding and propagation techniques can be listed (Table 2).

\section{Assessing whether Plant Breeding and Propagation Techniques Respect Integrity of Plants}

Below we discuss the consequences of assessing the existing breeding and propagation techniques at the plant and crop

Table 2. Levels and characteristics of the nature of plants and the resulting main principles and criteria for plant breeding and propagation methods derived from the integrity approach in organic agriculture.

\begin{tabular}{lc}
\hline Levels of integrity & The main criteria respecting the integrity of plants in organic plant breeding and propagation \\
\hline Integrity of life & The autonomy and the self-regulating ability of living entities should be respected. \\
Plant-specific integrity & $\begin{array}{c}\text { Breeding should improve and not reduce the ability to adapt and actively interact with the environment. The breeding } \\
\text { process should occur under organic soil conditions. Techniques should not affect the plant's potential for natural } \\
\text { reproduction. }\end{array}$ \\
$\begin{array}{l}\text { Genotypic integrity } \\
\text { Phenotypic integrity }\end{array}$ & $\begin{array}{l}\text { Crossing techniques should allow pollination, fertilization, embryo growth and seed formation on the (whole) plant. Selection } \\
\text { should focus on plant types that can maintain themselves and potentially can complete their life cycle in an organic } \\
\text { farming system. }\end{array}$ \\
\hline
\end{tabular}


Table 3. The consequences of acknowledging the integrity of plants for the compatibility of the different kinds of techniques with organic plant breeding and propagation. $\dagger$

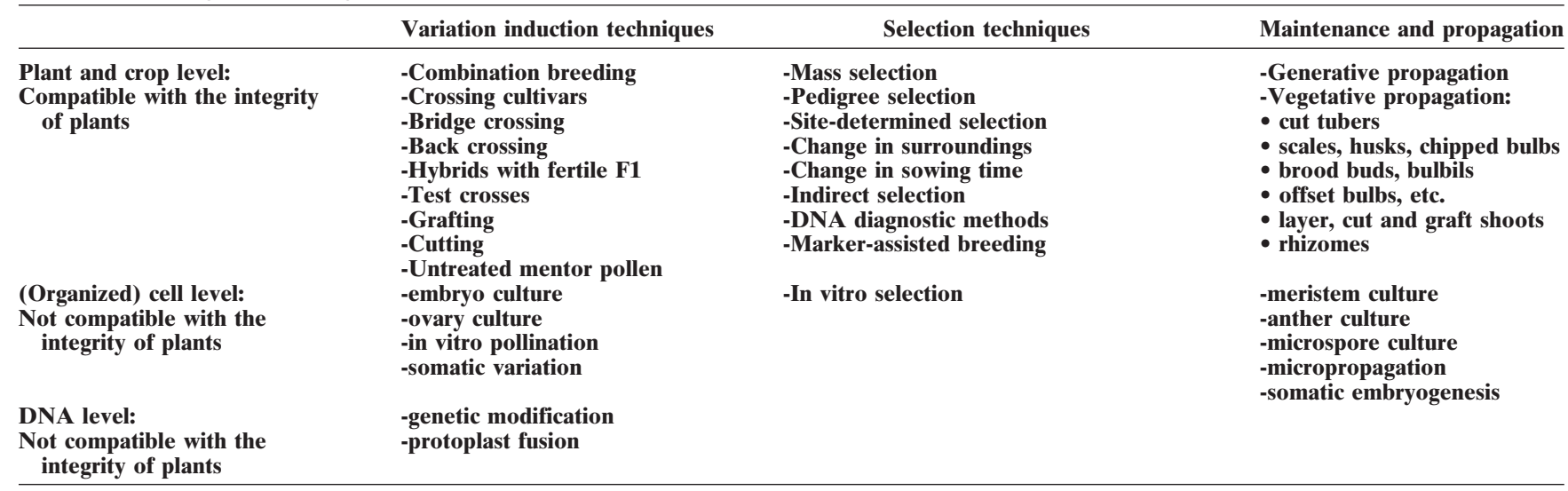

† A similar table, composed on the basis of ecological criteria, was published in the reports by Lammerts van Bueren et al. (1998 and 1999$)$ and has provided the basis for a draft by the International Federation of Organic Agriculture Movements for the Basic Standards on organic breeding and propagation (IFOAM, 2002).

level, the (organized) cell level, and the DNA-level, in light of the criteria of integrity of plants. This discussion is summarized in Table 3.

\section{Techniques at the Plant and Crop Level}

Conventional techniques at the plant and crop level listed in Table 3 are considered plant-worthy, whereas the newer techniques of tissue culture and genetic engineering are not. The acceptable techniques do not interfere with the plant's natural interaction with the soil (plant-specific integrity) or with reproductive barriers (genotypic integrity). They do not affect the wholeness of the plant (phenotypic integrity) when pollination, fertilization, and seed formation can occur on the whole plant itself. This also applies to several field selection methods, and multiplication and propagation techniques that allow the plant (or parts of plants) to grow in organically cultivated soil. These techniques can be used to maintain parental lines and to select and propagate progeny adapted to organic growing conditions. The maintenance of parental lines in vitro, as is done for some leek (Allium porrum L.) parents, is not in line with plant-specific integrity.

Taking the plant-specific integrity into account also includes the avoidance of techniques that reduce a plant's natural reproductive ability. Using cytoplasmic male sterility (CMS) in hybrids without restorer genes is not in line with the level of plant-specific integrity. The use of CMS in modern hybrids is growing, partly to simplify the procedure of hybridization, to reduce the percentage of undesired inbred plants (deviants) or simply to protect the seed sector (e.g., in the case of sorghum, where hybrid technology results in little heterosis). Although CMS occurs naturally in some species, like carrot (Daucus carota L.) and onion (Allium cepa L.), breeders use protoplast fusion to transfer the CMS characteristic to other species as well; for instance, from radish (Raphanus sativus L.) to cauliflower (Brassica oleracea L. var. botrytis L.). The use of CMS hybrids without restorer genes reduces the free access to the complete functional gene pool by other breeders. They can pass on their genes when used as a female parent, but a breeder cannot introduce a desired trait from CMS hybrids into his own breeding plant material separately from the CMS trait, as the CMS trait is transferred to the next generation through the cytoplasmic DNA of the female parent. The progenies of CMS hybrids without restorer genes are male sterile. This complication of the free exchange of the gene pool is not in line with the organic principles of sustainable breeding (genotypic integrity). Partly other ethical objections also exist to genetic male sterility and chemical male sterility. They do not apply to seedless fruits, like the bitter-free cucumber (Cucumis sativus L. var. sativus) cultivars. In this case, it concerns female-flowering cultivars, that can nevertheless bear fruit by parthenocarpy. Such cultivars can pass on their genes if a breeder crosses them with a monoecious or a maleflowering cucumber cultivar.

\section{Techniques at the Organized Cell Level}

Techniques at the organized cell level, or in vitro techniques such as embryo culture and ovary culture, concern hybridization, which in principle could occur under natural circumstances when enough plants are involved to allow the odd chance of success. Such hybridizations do not affect genotypic integrity because reproductive barriers are not crossed. But when such pollination occurs under in vitro conditions, it is not in compliance with plant-specific or phenotypic integrity. In embryo culture, the embryos resulting from pollination and fertilization on the plant are extracted and grafted on an artificial substrate where they are allowed to grow to maturity. The reproduction in the next generation can in principle occur naturally, on the plant. These have already been standard techniques in conventional plant breeding for many decades. They are applied to enlarge the success rate of certain crosses between related species and to speed up breeding programs, for example for the introduction of disease resistance from wild relatives of cultivated tomato.

For some life forms the cell is the smallest living, coherent entity with a more-or-less independent self-regulatory ability. This is not true for higher plants. Through cell and tissue cultures, the plant is reduced to its cellular potential and the natural environment is reduced to the artificial nutritional and growing conditions of a lab. This is very different from what the whole plant demands with respect to its physical, chemical, and biological environment from the perspective of organic agriculture. By using totipotent cell cultures, the differentiation processes of a plant in relation to time and to its natural (or organic) environment, which are characteristic of the development of plants, are temporarily eliminated, and thus, in principle, impair plant worthiness.

Embryo rescue, colchicine-induced chromosome doubling, and chemically induced mutation may be reruns of processes that incidentally occur in nature. Yet, these techniques still 
violate the plant-specific and phenotypic integrity of cultivated plants as they violate the nonchemical principle.

\section{Techniques at the DNA Level}

Techniques like protoplast fusion and genetic modification go a step further than embryo rescue tissue culture. These techniques are applied when two species differ so much that a successful cross cannot be achieved under natural circumstances. The techniques go beyond the level of the organized cell as the smallest living entity and affect a cell's coherence and organization. A protoplast is not even an integral cell, because the cell wall is dissolved, and naked cells are separated from the living context of the plant or tissue. Genetic engineering of higher plants is the process in which the genotype of the plant cell is altered by the introduction of an often alien gene or genes into the genome other than by sexual crossing. This definition includes the technique of protoplast fusion. With protoplast fusion and with genetic modification, genes are dissociated from the contexts of the natural plant $\times$ environment relation and of a living coherent cell or plant.

These techniques violate all levels of the nature of plants. They cross reproductive barriers (genotypic integrity) and go beyond the level of maintaining the integral, living cell. Therefore, they are associated with the nonliving level of nature (violating the integrity of life, plant-specific integrity, and phenotypic integrity). Genetic engineering is not compatible with the intrinsic value of plants.

\section{DNA Diagnostic Techniques}

DNA diagnostic techniques, which enable selection at the DNA level, do not involve genetic modification of crop plant DNA. The techniques, which are usually based on biochemical and molecular markers, could therefore be used in organic breeding programs to supplement trait selection methods in the field, but their potential for organic agriculture has yet to be proven. Genotype $\times$ environment interaction is of primary importance in organic plant breeding, and markers can contribute to assessment of environment-specific performance of genotypes. Some techniques used with DNA-diagnostics involve radioactive isotopes and carcinogenic chemicals, which are not used in organic agriculture.

\section{The Breeder's Eye}

Another aspect of breeding that needs to be addressed in the context of integrity of plants is the way plants are observed and assessed in the selection process. Plant breeding looks for equilibrium between plasticity and stability of the plant and its species-specific potential. Plants, in general, show a wide range of potential within the boundaries of the species. Breeders can affect the integrity of plants by applying breeding techniques that are not plant-worthy, and also by selecting plants that cannot maintain themselves in organic farming systems without chemical protectants. The breeder's attitude toward nature determines how he selects.

In addition to selection for quantitative traits (plant height, mass, dry weight, disease intensity, etc.), breeders usually have a total impression of their plants (the ideotype), and that can be seen as an aspect of the integrity of plants. Breeders develop a personal relationship with their plant object, based on their former and recent experiences and observations of plant performance in the field. Perceiving a specific kind of wholeness indicates that plants are more than the sum of isolated characteristics that can be registered by computers. The appreciation of the perception of wholeness of a plant depends on the breeder's individualized inner view of plants and on his personal, basic attitude toward nature. It can lead to extra parameters on the basis of experiential knowledge, relating to quality, disease resistance, and so on. It has to do with what breeders call the breeder's eye after years of personal dedication to and relationship with their crop, constantly comparing populations and knowing whether a plant deviates from or is in harmony with a certain dynamic, inner reference of a plant ideotype.

The recognition of a certain kind of pattern [see also Kiene (2001), De Vries (1999), and Baars (2002)] more-or-less explicitly results in an inner reference, built on the breeder's knowledge of and experience with the broad spectrum of potential appearances of progenies after hybridization. On the basis of this knowledge, the breeder perceives a more-or-less balanced or harmonious appearance of a plant in relation to its environment in the broadest sense (J. Velema, 2000, personal communication). This makes breeding, despite its scientific influences, always something of a skill or even an art, with a breeder trying to mold or create living material to conform to an image or an ideal in his mind (Duvick, 2002).

When the instrument of the breeder's eye is applied moreor-less consciously and this experiential knowledge is more systematized, it can lead to taking extra parameters into account or to a different evaluation of performance (Baars, 2002). In this context, authors like Holdrege (1996) and Hofmeister (1999) indicated the importance of a way of assessing whole-plant performance that is holistic and corresponds to the nature of the organisms of study. Organic breeders also rely on regular breeding techniques and methods and on quantitative yield data and laboratory results from testing the quality of their breeding lines and cultivars. There are, however, examples of organic breeders who also apply the principles of the integrity of plants and consciously try to develop and integrate such an image of a plant ideotype as a reference for the further development of new cultivars. They aim at finding the right balance between intended mass production, yield stability, and quality from a utility point of view (extrinsic value), and the intrinsic value and integrity of the plant. This implies the ability of a plant or cultivar to develop in an optimal, species-specific balance between growth, differentiation, and ripening under the influence of its environment (Bockemühl, 1983; Kunz, 1983). This approach does not mean that these breeders have a fixed image of species-specific plant performance. Respecting the integrity of plants is a prerequisite for organic breeders, helping them to make their personal selection to serve the continuously evolving species.

\section{DISCUSSION AND CONCLUSIONS}

Taking the intrinsic value of plants seriously in the sense that one links it with restrictive consequences is still a sensitive issue in public and especially in scientific debates. Because organic agriculture also applies ethical principles, their explicitation is necessary to understand why members of the organic movement voluntarily restrict their options and search for other strategies. Although scientists tend to ignore the impact of underlying ethical principles in their strive for value-free science (Wirz \& Lammerts van Bueren, 1997; Baars, 2002), it is also essential in science to clarify values behind strategies to enable other scientists to understand, criticize, and collaborate.

While the conceptualization of the intrinsic value and integrity of animals has already resulted in governmental regulations, the discussion about plants is still in its incipient stage. Hofmeister (1999) and other authors 
pointed out that the attitude in society is increasingly shifting toward a biocentric perspective that recognizes not only the intrinsic value of animals but also that of plants. Such authors describe several inherent characteristics of the nature of plants that should be respected: their autonomy, otherness, and ability for self-reproduction. Herein, we made ongoing discussions more transparent by trying for the first time to systematically conceptualize intrinsic value and integrity of plants, and to derive criteria for assessment. We applied bioethical principles to the field of organic plant breeding and propagation. Distinguishing different levels of integrity of plants made it possible to instrumentalize the concept of integrity and derive criteria to assess whether breeding and propagation techniques comply with organic principles of respect for integrity of plants. Evaluating breeding and propagation techniques on the basis of the criteria derived from the principles of integrity of plants does not lead to the same list of techniques acceptable in organic agriculture as the earlier assessment based on ecological criteria in Lammerts van Bueren et al. (1998 and 1999). The main difference is the assessment of in vitro techniques. On the basis of ecological criteria of organic farming, one may consider in vitro techniques not compatible because of the use of artificial growing media. The application of these techniques is an ecological detour, yet one that still operates within the level of life, albeit the lowest integration level (i.e., of organized cells). From the principles of integrity of plants there are much clearer arguments against in vitro techniques, as they affect the plant-specific and phenotypic integrity of plants.

From a conventional, anthropocentric point of view, taking integrity into account merely restricts the tools for breeders. From an organic, biocentric point of view, however, it challenges the life sciences to participate in the ongoing discussion and to develop new breeding and propagation strategies within the framework of the principles of naturalness to gain the desired progress in organic production.

The practical consequences of the concept of integrity are not immediate, because breeding and seed production activities specifically for organic agriculture (even those merely based on the principles of the nonchemical and agroecological approaches) are still in their infancy. Making the criteria of intrinsic value and integrity of plants more explicit and combining the ethical approach to the already established nonchemical and agroecological ones will assist those breeders willing to participate in organic plant breeding, to develop adequate breeding strategies for organic cultivars. Distinguishing the three different approaches to naturalness in organic agriculture and the consequences for the breeding and propagation strategies can also help distinguish short-term and long-term steps for the practical development of organic plant breeding and seed production. Some breeding companies start with the nonchemical approach, others include the agroecological approach, and some accept the more challenging integrity approach in breeding.

Taking all three approaches to naturalness into ac- count, the aims of organic plant breeding can be summarized as follows: Plant breeding for organic agriculture produces cultivars with a good nutritional value and taste, enhances the potential for a sound organic seed production and farming system, and enhances biodiversity. Organic plant breeding follows the concept of naturalness by avoiding the use of chemical inputs, by stimulating the agroecological self-regulatory ability of organic farming systems, and by respecting the integrity of plants based on respect for their natural reproductive ability and barriers, and their relationship with the living soil.

\section{ACKNOWLEDGMENTS}

The authors are grateful to the Louis Bolk Institute (Driebergen, the Netherlands), the Iona Foundation (Amsterdam, the Netherlands), and the Triodos Foundation (Zeist, the Netherlands) for partly funding this study. We are also thankful for the critical and constructive comments of J.M.M. van Damme, S. Lijmbach, P. Stam, J. Velema, H. Verhoog, and the three anonymous referees on earlier versions of this paper.

\section{REFERENCES}

Anonymous. 1981. Nota 'Rijksoverheid en Dierenbescherming'. Ministerie van Cultuur, Recreatie en Maatschappelijk Werk, Den Haag, the Netherlands.

Anonymous, 1991. Council Regulation (EEC) No 2092/91 of 24 June 1991 on organic production of agricultural products and indications referring thereto on agricultural products and foodstuffs, including all amendments. Official Journal No L 198, 22.7.1991. European Economic Community, Brussels, Belgium.

Anonymous. 1999. An ethical foundation for genetic engineering choices. Danish Ministry of Trade and Industry, Copenhagen.

Baars, T. 2002. Reconciling scientific approaches for organic farming research. Part I and Part II. Ph.D. thesis. Wageningen Univ., Wageningen, the Netherlands (Diss. Abstr. 3326).

Bockemühl, J. 1983. Vergleiche zwischen Wild- und Kulturformen zum Verständnis der Nahrungspflanze und zum Finden einer Zielrichtung für die Züchtung. Elem. Naturwissenschaft 39:1-14.

Brom, F.W.A. 1999. The use of 'intrinsic value of animals' in the Netherlands. p. 15-28. In M. Dol et al. (ed) Recognizing the intrinsic value of animals, Van Gorcum, Assen, the Netherlands.

Brom, F.W.A., and E. Schroten. 1993. Ethical questions around animal biotechnology. The Dutch approach. Livest. Prod. Sci. 36:99-107.

Bullard, L., B. Geier, F. Koechlin, D. Leskin, I. Meister, and N. Verhagen. 1994. Organic agriculture and genetic engineering. Ecol. Farming 8:25-26.

De Cock Buning, T.J. 1999. The real role of 'intrinsic value' in ethical review committees. p. 133-139. In M. Dol et al. (ed.) Recognizing the intrinsic value of animals. Van Gorcum, Assen, the Netherlands.

De Vries, A. 1999. Try-out: Ontwikkelen van reflexieve professionaliteit, contouren van ervaringswetenschap. Stichting Onderzoek in eigen werk, Arnhem, the Netherlands.

Duvick, D.N. 2002. Theory, empiricism and intuition in professional plant breeding. p. 189-211. In D.A. Cleveland and D. Soleri (ed.) Farmers, scientists and plant breeding - Integrating knowledge and practice. CABI Publishing, Wallingford, UK.

Heaf, D., and J. Wirz (ed.) 2001. Intrinsic value and integrity of plants in the context of genetic engineering. p. 32-35. In Proc. of the Ifgene Workshop. 9-11 May 2001. Natural Science Section, Dornach, Switzerland.

Hofmeister, G. 1999. Ethikrelevantes Natur- und Schöpfungsverständnis: Umweltpolitische Herausforderungen, naturwissenschaftlich-philosophische Grundlagen, schöpfungstheologische Perspectiven, Fallbeispiel: Grüne Gentechnik. Peter Lang (Europaischer Verlag der Wissenschaften), Frankfurt am Main, Germany.

Holdrege, C. 1996. Genetics and the manipulation of life: The forgotten factor of context. Lindesfarne Press, Hudson, NY.

IFOAM. 2002. Basic standards for organic production and processing 
[Online]. [1 p.] Available at: www.ifoam.org (cited Feb. 2003; modified 30 April 2003; verified 5 May 2003). International Federation of Organic Agriculture Movements, Tholey-Theley, Germany.

Jongerden, J., C. Almekinders, and G. Ruivenkamp. 2002. Over visies en nieuwe wegen-Case studies van organisatievormen in de biologische veredeling en zaadproductie. Rapport no. 182. Wetenschapswinkel WUR, Wageningen, the Netherlands.

Kiene, H. 2001. Komplementäre Methodenlehre der klinische Forschung. Cognition-based medicine. Springer Verlag, Berlin.

Kockelkoren, P.J.H. 1993. Van een plantaardig naar een plant-waardig bestaan. Ethische aspecten van biotechnologie bij planten. Ministerie van Landbouw, Natuurbeheer en Visserij, Den Haag, the Netherlands.

Kockelkoren, P.J.H. 1995. Ethical aspects of plant biotechnologyReport for the Dutch Government commission on ethical aspects of biotechnology in plants. Appendix 1. In Agriculture and spirituality, essays from the Crossroad Conference at Wageningen Agricultural University. International Books, Utrecht, the Netherlands.

Kunz, P. 1983. Entwicklungsstufen bei Gerste und Weizen- ein Beitrag zu einem Leitbild für die Züchtung. Elem. Naturwissenschaft 39: 23-37.

Lammerts van Bueren, E.T., M. Hulscher, J. Jongerden, M. Haring, J. Hoogendoorn, J.D. van Mansvelt, and G.T.P. Ruivenkamp. 1998. Sustainable organic plant breeding. Subproject 1. Discussion paper: Defining a vision and assessing breeding methods. Louis Bolk Inst., Driebergen, the Netherlands.

Lammerts van Bueren, E.T., M. Hulscher, J. Jongerden, G.T.P. Ruivenkamp, M. Haring, J.D. van Mansvelt, and A.M.P. den Nijs. 1999. Sustainable organic plant breeding. p. 32-35. In Final report: A vision, choices, consequences and steps. Louis Bolk Inst., Driebergen, the Netherlands.

Lammerts van Bueren, E.T., and L. Luttikholt. 2001. Standpuntbepalingen met betrekking tot biologische plantenveredeling en veredelingstechnieken in 2001. Louis Bolk Inst., Driebergen, the Netherlands.

Lammerts van Bueren, E.T., P.C. Struik, and E. Jacobsen. 2002a.
Ecological concepts in organic farming and their consequences for an organic ideotype. Neth. J. Agric. Sci. 50:1-26.

Lammerts van Bueren, E.T., P.C. Struik, and E. Jacobsen. 2002b. Genetic variation in an organic variety concept. p. 63-81. In E.T. Lammerts van Bueren, Concepts and strategies of organic plant breeding and propagation. Ph.D. thesis. Wageningen Univ. (Diss. Abstr. 3329), Wageningen, the Netherlands.

Lammerts van Bueren, E.T., P.C. Struik, and E. Jacobsen. 2003. Organic propagation of seed and planting material: An overview of problems and challenges or research. NJAS, Wageningen J. Life Sci. (in press).

Lammerts van Bueren, E.T., K.-P. Wilbois, L. Luttikholt, E. Wyss, and L. Woodward. 2001. Short report on the results of the international workshop on organic plant breeding techniques, Driebergen, the Netherlands [Online]. [4 p.] Available at: http://www.eco-pb.org/ 09/nl_01_02_report.pdf (cited Feb. 2003; verified 13 May 2003). ECO-PB, Frankfurt, Germany.

Meyer-Abbich, K.M. 1997. Praktische Naturfilosophie: Erinnerung an einen vergessenen Traum. Beck, München, Germany.

Rutgers, B., and R. Heeger. 1999. Inherent worth and respect for animal integrity. p. 41-51. In M. Dol et al. (ed.) Recognizing the intrinsic value of animals. Van Gorcum and Co., Assen, the Netherlands.

Verhoog, H. 1992. The concept of intrinsic value and transgenic animals. J. Agric. Environ. Ethics 5(2):147-160.

Verhoog, H. 2002. GMO's in de landbouw: Maatschappelijke en ethische aspecten. COGEM, Bilthoven, the Netherlands.

Verhoog, H., M. Matze, E.T. Lammerts van Bueren, and T. Baars. 2003. The role of the concept of the natural (naturalness) in organic farming. J. Agric. Environ. Ethics 16:29-49.

Wirz, J., and E. Lammerts van Bueren (ed.) 1997. The future of DNA. Proceedings of an international Ifgene conference on presuppositions in science and expectations in society. Kluwer Academic Publ., Dordrecht, the Netherlands.

Zweers, W. 1989. Houdingen ten opzichte van de natuur. Heidemij Tijdschrift 100(3):74-80.

Zweers, W. 2000. Participating with nature. Outline for an ecologization of our world view. International Books, Utrecht, the Netherlands. 